\title{
Applying Grey Forecasting Model on the Investment Performance of Markowitz Efficiency Frontier: A Case of the MSCI World Index
}

\author{
Alex Kung-Hsiung Chang ${ }^{1}$ \\ Chueh-Chi Chen ${ }^{2}$ \\ ${ }^{\mathbf{1}}$ Professor of Department of Business Administration \\ ${ }^{2}$ Graduate Student of Department of Business Administration National Pingtung University of Science and \\ Technology
}

\begin{abstract}
This paper uses a grey forecasting model $\operatorname{GM}(1,1)$ on improving the investment performance of classical Markowitz efficiency frontier's investment portfolio using the component markets' indexes of MSCI World Index from 1999 to 2005 as the samples. Using grey Markowitz efficiency frontier's investment portfolio models, we establish a more stable and correct connection between ex-ante model and ex-post performance. The results show the Grey Markowitz efficiency frontier investment portfolio model could improve the investment performance effectively and stably.
\end{abstract}

Keywords: Grey forecasting model, $\operatorname{GM}(1,1)$, Markowitz efficiency frontier, Investment portfolio.

\section{Introduction}

With the growing globalization of financial markets and information transmission technology has been accompanied. A growing efficiency of information transmission between international financial markets has been formed. (Chang, Chou, and $\mathrm{Wu}, 2000)$ Better understanding of the nature of investment portfolio could be helpful to international investors and policy makers alike. With respect to policy maker, to know the market interaction that promotes efficiency could be helpful to control undesirable side effects. Likewise, investment and hedging strategies could be more effective if the nature of market portfolio effectiveness were better understood.

Separation theorem by Markowitz (1952) was the foundation of modern invention theory. The capital asset pricing model (CAPM) became the important pricing model on assets after florence of Tobin (1965) and Sharpe (1964).
Due to the close relationship between the systematic risk coefficient $\beta$ and asset'returns, a lot of papers have discussed it since the 1960s. Original CAPM founded on ex-ante sincerely hypothesis, cause to a problem of using a simple model to estimate a complex economics. That confuses many scholars. In 1970s, Blume and Friend (1973) found that beta estimation was greater than the real figure if it had a big beta, and would be smaller if it had a small one.

A lot of empirical research found a paradox between the ex-ante Markowitz efficiency portfolio model and the real investment performance after that.

see Douglas, 1969; Chan and Lakonishok, 1992

The noise between that resulted from self-correlation of asset' returns, time varying of betas estimation

likes Brennan, 1988; Chen, Lee, and Yeh, 2002 , thin trading (or trading delays, like Fabozzi and Francis, 1978), and infrequent trading.

Academics and practitioners have extensively discussed modified models over the past 30 years. Thought the paradox existed several years, no one could replace the original CAPM, and improve the paradox between ex-ante model and ex-post performance. This paper tries to build a grey forecasting model to correct the inconsistent phenomenon and improve the investment performance of efficiency frontier in CAPM effectively and stably. In the study intending to eliminate noise, increase accuracy of forecasting effectiveness. The Grey forecasting model was used in the VAR model first.

Chang, 1997; Chang and $\mathrm{Wu}, 1998$; Chang, $\mathrm{Wu}$, and Lin, 2000 The results show that the Grey forecasting model could capture the securities price impulse, made the prices discovering process more stable. The out-of-the-period forecasting accuracy had been increased.

Grey theorem founded by Deng (1988) has been applied in research in agriculture, engineering (Deng et al, 1999), but scarcely in business, especially finance. Chang (1997) applied GM $(1,1)$ in the study of transmission mechanism between security market, 
monetary market, and foreign exchange market in a VAR model. The result showed that GVAR could eliminate noise of markets, increase the accuracy of forecasting stock prices in the out-of-the-period.

Chang and $\mathrm{Wu}$ (1998) discussed seasonality about the Chinese Festival in Taiwan's Security Market using the Grey Forecasting Model. The results showed that the forecasting accuracy was better than that of a Moving Average Model. Chang (2004; 2005) applied GM $(1,1)$ in the study of systematic risk coefficient forecasting. Using the Dow Jones Industrial Index' Component Securities and the MSCI World Index from 1998 to 2003 as samples, the author found that forecasting effectiveness and efficiency from the Grey Forecasting Model on forecasting the systematic risk coefficient are clearly excellent. The Grey Forecasting Model on forecasting systematic risk coefficient is a suited and good model.

This study wants to build a Grey Markowitz efficiency frontier's investment portfolio and modifies the original one in order to eliminate deviation between ex-ante model and ex-post performance effectively. Sector 2 presents methodology, sector 3 presents the results of study, and sector 4 presents conclusion.

\section{Methodology}

This study samples the MSCI World Index from 1999 to 2005. 62 securities are sampled and offered after 1999.5. First, the raw daily returns of samples are whitened using a GM $(1,1)$. And the grey variances and covariances are computed. Four investment portfolios are constructed using raw variances and covariances and grey variances and covariances. Portfolio A is the original efficiency frontier's investment portfolio of CAPM, portfolio B is the grey efficiency frontier's investment portfolio of CAPM using raw covariances and grey variances, portfolio $\mathrm{C}$ is the grey efficiency frontier's investment portfolio of CAPM using raw variances and grey covariances, and portfolio D is the grey efficiency frontier's investment portfolio of CAPM using grey variances and covariances. See figure 1.

In order to examine the effectiveness and efficiency of grey efficiency frontier's investment portfolios, this paper compares the four investment portfolios' performance on the market portfolio point (M point), the minimum variance portfolio point (MVP point), and the maximum return portfolio point (X point) using the Sharpe Index, Treynor Index and Jensen Index. Three hypotheses are set as,
Hypothesis I: The grey portfolios have lower variance than the original portfolio on the minimum variance portfolio point (MVP point).

Hypothesis II: The grey portfolios have higher investment performance than the original portfolio on the market portfolio point (M point).

Hypothesis III: The grey portfolios have higher return than the original portfolio on the maximum

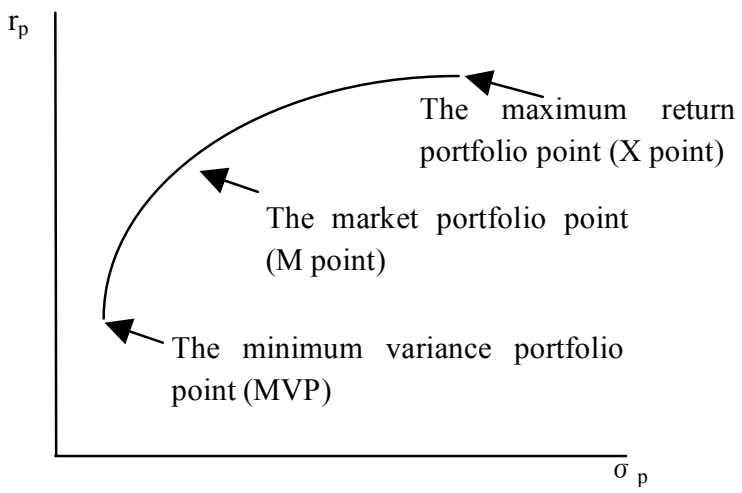

return portfolio point (X point).

Figure 1 The Markowitz's Efficiency Frontier

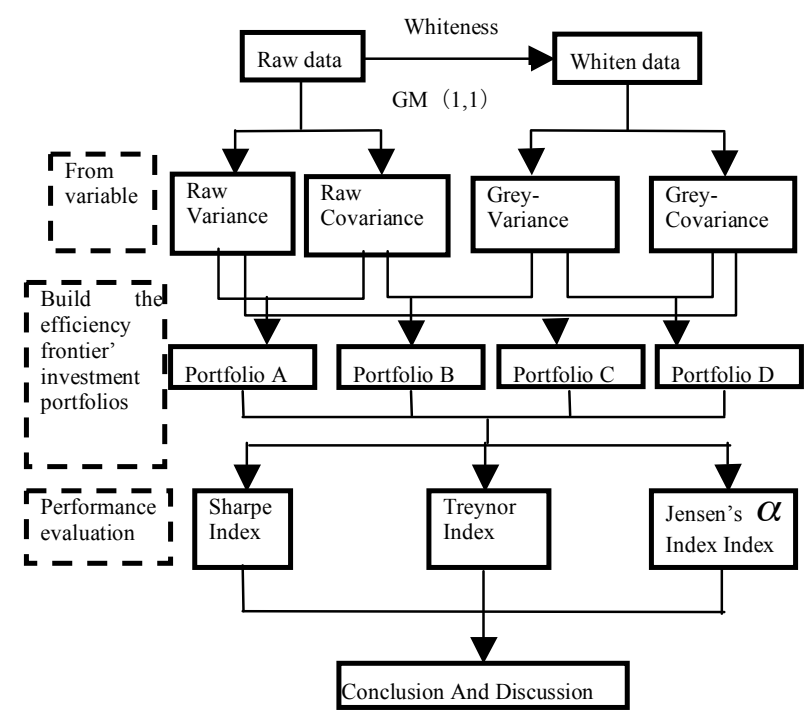

Figure 2 The Study Frame

In the study schedule, one-year data are used to build investment portfolios on the efficiency frontier. The performance comparisons are examined by pairwise $t$ examination during next one month on the minimum variance portfolio point (MVP point), the market portfolio point ( $\mathrm{M}$ point), and the maximum return portfolio point ( $\mathrm{X}$ point). Rolling per single month each time, 62 examination periods are studied in this paper. See figure 3 . 


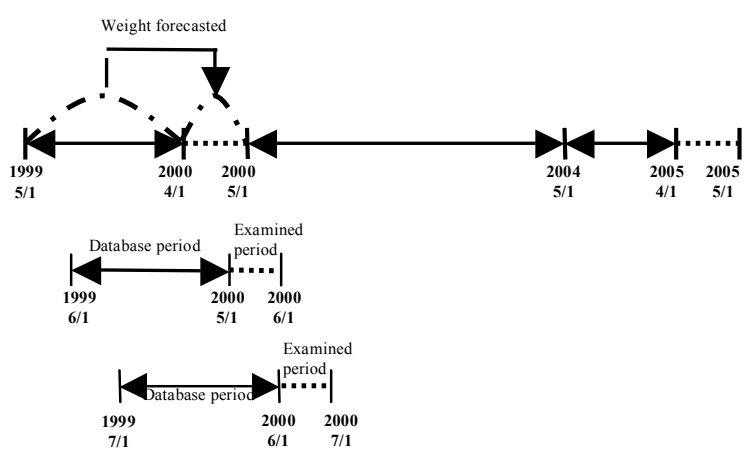

Figure 3 The Rolling Study Schedule

\section{Results}

First of all, we observe the numbers that superior and inferior number of grey portfolios than original portfolio separately. See table 1, on the MVP, grey portfolios B is superior to original portfolio A using Sharpe index. Grey portfolios B and D's investment performance are superior to original portfolio A using Treynor index and Jensen index.

On the market portfolio point, grey portfolios B's investment performance is superior to original portfolio A using Sharpe index, Treynor index, and Jensen index. Grey portfolio D's investment performance is superior to original portfolio A using Jensen index. And on the maximum return point, the grey portfolio' investment performance is superior to original portfolio A using Jensen index, but inferior to original portfolio A using Sharpe and Treynor Index.

By using pairwise $t$ examinations, we compare investment performances between grey Markowitz efficiency frontier's investment portfolios and original portfolio.

Table 1: A comparison of investment performance evaluation between grey portfolios and original portfolio

\begin{tabular}{llll}
\hline & MVP & M & X \\
\hline Panel A: Sharpe Index & & & \\
B & $41(21)$ & $40(22)$ & \\
C & $31(31)$ & $31(31)$ & \\
D & $30(32)$ & $30(32)$ & $30(31)$
\end{tabular}

\begin{tabular}{llll} 
D & $30(32)$ & $30(32)$ & $30(31)$ \\
\hline Panel B: Treynor Index & & & \\
B & $35(27)$ & $32(30)$ & \\
C & $28(34)$ & $27(35)$ & \\
D & $31(31)$ & $28(34)$ & $23(26)$ \\
\hline
\end{tabular}

Panel C: Jensen Index

\begin{tabular}{llll} 
B & $36(26)$ & $39(23)$ & \\
$\mathrm{C}$ & $30(32)$ & $27(35)$ & \\
$\mathrm{D}$ & $32(30)$ & $32(30)$ & $32(21)$ \\
\hline
\end{tabular}

Note: The pair wise numbers in table denotes the superior and inferior number of grey portfolios than original portfolio separately.
Table 2 show the $\mathrm{t}$ examination of comparing variance between grey portfolios and original portfolio on the MVP. Grey portfolio B has higher variance than original portfolio $\mathrm{A}$, but grey portfolio $\mathrm{C}$ has lower variance than original portfolio A significantly.

Table 3 show the $t$ examination of comparing investment performances between grey portfolios and original portfolio on the market portfolio point using Sharpe index, Treynor index, and Jensen index separately. Grey portfolio D has higher investment performance than original portfolio A significantly by Treynor index. And grey portfolio B has higher investment performance than original portfolio A significantly by Sharpe index, Treynor index and Jensen index separately.

The $t$ examination of comparing investment return shows that the grey portfolio has lower investment return than the original portfolio on the maximum return point. The $\mathrm{t}$ value -0.4308 is not significant at $10 \%$ level.

The results show that the grey investment portfolios on Markowitz efficiency frontier are effective and stable model than the original investment portfolio, portfolio B is the best one specially.

Table 2 : The $t$ examination of comparing variance between grey portfolios and original portfolio on the MVP

\begin{tabular}{lllll}
\hline & $\mathrm{A}$ & $\mathrm{B}$ & $\mathrm{C}$ & $\mathrm{D}$ \\
\hline Variance & 0.001742 & 0.001834 & 0.001547 & 0.001748 \\
$\mathrm{t}$ & & $2.52179^{* * *}$ & $-4.54693 * * *$ & 0.18128 \\
\hline
\end{tabular}

Notes: 1. Portfolio A is the original Markowitz efficiency frontier's investment portfolio, portfolio B is the grey Markowitz efficiency frontier's investment portfolio using raw covariances and grey variances, portfolio $\mathrm{C}$ is the grey Markowitz efficiency frontier's investment portfolio using raw variances and grey covariances, and portfolio D is the grey Markowitz efficiency frontier's investment portfolio using grey variances and covariances.

2. The * denotes significant at $10 \%, * *$ denotes significant at $5 \%$, and $* * *$ denotes significant at $1 \%$.

Table 3 : The t examination of comparing investment performance indexes between grey portfolios and original portfolio on the market portfolio point

\begin{tabular}{lllll}
\hline & $\mathrm{A}$ & $\mathrm{B}$ & $\mathrm{C}$ & $\mathrm{D}$ \\
\hline $\begin{array}{l}\text { Sharpe } \\
\text { Index }\end{array}$ & -0.017040 & 0.0300164 & -0.0368446 & -0.02167 \\
$\mathrm{t}$ & & $2.5881^{* * *}$ & -0.5028 & -0.3849 \\
\hline $\begin{array}{l}\text { Treynor } \\
\text { Index }\end{array}$ & -0.014742 & 0.009839 & 0.0006931 & 0.034358 \\
$\mathrm{t}$ & & $1.7756^{* *}$ & 1.1904 & $1.5646^{*}$ \\
\hline $\begin{array}{l}\text { Jensen } \\
\text { Index }\end{array}$ & -0.000079 & -0.000031 & -0.0002185 & -0.000072 \\
$\mathrm{t}$ & & $1.4418^{*}$ & -1.6786 & 0.3609 \\
\hline
\end{tabular}

Notes: The same with Table 2. 


\section{Concluding Remark}

Using component securities of the MSCI World Index from 1999 to 2005 as the samples, we use a grey forecasting model $\operatorname{GM}(1,1)$ on improving the investment performance of classical Markowitz efficiency frontier's investment portfolio.

We observe the numbers that superior and inferior number of grey portfolios than original portfolio first. In genernal, the grey portfolios' investment performance is superior to original portfolio on the MVP and market portfolio point.

Next, we use $t$ examination to compare investment performances between grey portfolios and original portfolio using Sharpe index, Treynor index, and Jensen index separately. The results show that the grey investment portfolios on Markowitz efficiency frontier are effective and stable model than the original investment portfolio on the MVP, and market portfolio point.

Base on the study results, hypothesis III is supported weakly, and hypothesis I and II are supported strongly. Especially, a grey Markowitz investment portfolio model B using raw covariances and grey variances, is the best one that constructs a more stable and correct connection between ex-ante model and ex-post performance.

\section{References}

[1] Brennan, M.J., and T.E. Copeland, "Beta Changes Around Stock Splits: A Note," The Journal of Finance, Vol. 43, No.4, pp.1009-1013 (1988).

[2] Blume, M.E. and I. Friend, "A New Look at the Capital Asset Pricing Model," Journal of Finance 28(1), pp.19-33 (1973).

[3] Chang, K.H., A Grey VAR Model on Information Mechanism of Monetary Markets in Taiwan, Doctor Dissertation, National Sun YatSen University (1997).

[4] Chang, K.H., "Applying Grey Forecasting Model on the Systematic Risk Estimation: A Study of the MSCI World Index' Component Securities", Journal of Grey System and Uncertainty, Vol. 7, No. 2, pp.113-120 (2004).

[5] Chang, K.H., "Applying Grey Forecasting Model on the Systematic Risk Estimation: A Case of the MSCI World' Component SecuritiesMarkets", Journal of Grey System and Uncertainty, Vol. 8, No. 1, pp.1-13 (2005).

[6] Chang, K.H. and C.S. Wu, "A Grey Time Series Model on Forecasting the Chinese New Year Effect in the Taiwan Stock Market," Journal of The Chinese Grey System Association, pp.55-63 (1998).
[7] Chang, K.H., S.L. Chou, and C.S. Wu, "international Transmission of Stock Market Movements within the Great China Economic Area," PanPacific Management review Vol 3, No.2, pp.283-298 (2000).

[8] Chang, K.H., C.S. Wu, and T.Y. Lin, "A Grey VAR Forecasting Model on the Long-term Information Transmission Mechanism intra the Taiwan Stock Market," Journal of Management, Vol.17, No.4, pp.591-623 (2000).

[9] Chen, A.L., W.J. Lee, and J.K. Yeh, "A Study of Systematic Risk Impact to Stocks Return: Holding Horizon Analysis," Chinese Management Review, Vol.4, No.4, pp.1-14 (2002).

[10] Deng J. et al., Essential Tropics on Grey System, Beijing: China Ocean Press (1988).

[11] Deng, Kao, Wen, Chang, and Chang, Grey Forecasting Methods and Applications, Taipei: Kao-Lih Press co. (1999).

[12] Douglas, G.W., "Risk in the Equity Markets: An Empirical Appraisal of Market Efficiency," Yale Economic Essays, pp.30-45 (1969).

[13] Frank, J. F. and J.C. Francis, "Beta as a Random Coefficient," The Journal of Financial and Quantitative Analysis," Vol. 13, No. 1, pp.101116 (1978).

[14] Louis K. C., Chan and Josef Lakonishok, "Robust Measurement of Beta Risk," The Journal of Financial and Quantitative Analysis, Vol. 27, No. 2, pp.265-282 (1992).

[15] Lue, J.B., Time-variant Market Risk Estimation - A Case of Taiwan Stock Market, Master Dissertation, National Kaohsiung First University of Science and Technology (2002).

[16] Markowitz, H. M., "Portfolios Selection," Journal of Finance, Vol.7, No.1, pp.77-91 (1952).

[17] McInish, T.H. and R.A. Wood, "Adjusting for beta bias: An assessment of alternate techniques: A note,"Journal of Finance, Vol.1, No.41, pp.277-286 (1986).

[18] Sharpe, W. F., "Capital Asset Price: A Theory of Market Equilibrium under Conditions of Risk," Journal of Finance, Vol.19, No.3, pp.425-442 (1964).

[19] Tobin, J. "The Theory of Portfolio Selection," in The Theory of Interest Rates, ed. By F.H. Hahn and F.P.R. Brechling, London: Macmilla Co. Ltd., (1965).

[20] Wen, K.L., Grey Systems: Modeling and Prediction, Yang's Scientific Research Institute, LLC (2004). 